\title{
Pyroclastic material from the Puyehue-Cordon-Caulle Volcanic Complex, Chile, as carrier of Beauveria bassiana conidia: Potential utilization in mycoinsecticide formulations
}

\author{
Santiago Schalamuk ${ }^{1^{*}}$, Sebastián Pelizza ${ }^{2,3}$, Ana Clara Scorsetti \\ María José González ${ }^{1,4}$, Irma Lía Botto ${ }^{1}$ \\ ${ }^{1}$ CEQUINOR (CCT-La Plata-CONICET-UNLP), La Plata, Argentina; *Corresponding Author: sschala@yahoo.com.ar \\ ${ }^{2}$ Instituto Spegazzini (UNLP), La Plata, Argentina \\ ${ }^{3}$ CEPAVE (CCT-La Plata-CONICET-UNLP), La Plata, Argentina \\ ${ }^{4}$ INREMI (CICPBA-UNLP), La Plata, Argentina
}

Received 7 October 2013; revised 18 November 2013; accepted 30 November 2013

Copyright (C 2014 Santiago Schalamuk et al. This is an open access article distributed under the Creative Commons Attribution License, which permits unrestricted use, distribution, and reproduction in any medium, provided the original work is properly cited. In accordance of the Creative Commons Attribution License all Copyrights (C) 2014 are reserved for SCIRP and the owner of the intellectual property Santiago Schalamuk et al. All Copyright (C 2014 are guarded by law and by SCIRP as a guardian.

\section{ABSTRACT}

The last volcanic eruption of the Puyehue-Cordon-Caulle Volcanic Complex in the Andes cordillera of western South America, occurring on 4 June 2011, ejected pyroclastic materials that were accumulated in a wide region of the northern Patagonia (Argentina), affecting the environment and health of residents within the area. The aim of this work was to evaluate the practicability of using this waste material as a lowcost carrier for mycopesticide formulations. Beauveria bassiana is a recognized fungal agent for arthropod biologic control. Lengthy storage is critical for the development of mycoinsecticide formulations. Accordingly, the search for adequate materials to improve the shelf life of biocontrol products becomes desirable. First, several analytical techniques were employed to characterize the pyroclast physicochemically; then the viability of the fungal conidia was evaluated after an 18-month storage in the volcanic material. Finally, the pathogenicity of the conidia after that prolonged maintenance in the vehicle was assessed on the beetle Alphitobius diaperinus, an insect pest in poultry houses that causes major economic losses. The results from those bioassays proved auspicious for the eventual utilization of the pyroclast as a bioinsecticide carrier especially since the formulation had proven to be stable for at least 18 months under a wide range of environmental conditions. The constant moisture in a closed environment within a $5^{\circ} \mathrm{C}-40^{\circ} \mathrm{C}$ temperature range insures a viable state during storage. The results indicate that what would otherwise be volcanic waste may be utilized as an efficient, abundant, inexpensive, and environmentally innocuous carrier of entomopathogenic fungi.

\section{KEYWORDS}

Volcanic Material; Bioinsecticide; Entomopathogenic Fungi; Viability; Vehicle

\section{INTRODUCTION}

The Andes cordillera in western South America is one of the most active tectonic and volcanic regions worldwide. The stratovolcano-part of the Puyehue-CordonCaulle Volcanic Complex (PCCVC), Chile (40³4'57"S, 7206'53"W; 2236 meters above sea level)_has been active since the Miocene Epoch. The last volcanic eruption, occurring on 4 June 2011, ejected pyroclastic materials that were dispersed by the wind to accumulate in a wide region of the northern Patagonia (Argentina) [1]. The volcanic event not only affected the environment and the health of residents within the area, but also had negative effects on local and regional economies (related to agriculture, livestock, and fishing, among other natural commodities). Though volcanic ash always constitutes a significant environmental hazard [2]; nevertheless, upon 
consideration of that pyroclast's high abundance and low cost of extraction, several investigations have been directed at analyzing the potential use of the ash as raw material for the development of different technological processes (e.g., in adsorbents and binders and as substrates). Different geomaterials (mainly stable mineral species) as well as organic and inorganic compounds are employed as vehicles for agrochemicals and biopesticides, with silicates being the most commonly used because of their properties, stability, abundance, and low cost [3]. In recent years, the use of microbial biocontrol agents such as bacteria, viruses, and fungi has raised interest as alternatives for reducing the use of chemical pesticides in integrated pest-management programs [4,5]. The development of fungal biocontrol formulations with clay minerals as carriers has highlighted the low environmental impact relative to other types of vehicles [6]. To the best of our knowledge, however, no information is as yet available on the utilization of pyroclastic material (ashes and pumices) for that purpose.

Among biocontrol agents, entomopathogenic fungi have attracted considerable attention as potential regulators of insect populations [7,8]. More than 100 insect biocontrol products based on those types of fungi are commercially available worldwide [9]. The fungus Beauveria bassiana is one of the most promising agents for biologic control of arthropods because of its persistance in the host population, the high mortality rates it causes in larvae and adults, and its facile dispersion [10]. For an effective control to be achieved, however, the asexual spores or conidia - the infective units-must retain a high viability (i.e., the ability to germinate) and virulence (pathogenicity) against the target pest during sometimes prolonged storage before being dispersed in the field [11]. Within this context, research on potential inorganic carriers will be required before effective pest management can be achieved through the use of biocontrol agents. Moreover, a knowledge of the physicochemical properties of the carriers of entomopathogenic agents is essential for understanding the conditions affecting the shelf life and persistence of biocontrol products as well as the effect of their application to the environment.

The aim of this work was therefore to evaluate the practicability of using volcanic material from the recent eruption within the PCCVC as a low-cost carrier for Beauveria bassiana conidia. Several analytical techniques-e.g., inductively coupled plasma atomic-emission spectroscopy (ICP-AES), differential thermal gravimetry, X-ray diffraction, scanning electron microscopy (SEM), Braunauer-Emmet-Teller (BET) adsorption, Raman spectroscopy, and particle-size-distribution measurement-were employed for physicochemical characterization of the pyroclast; the viability of the fungal conidia was evaluated after storage for 18 months in the volcanic material; and the pathogenicity of the conidia after that prolonged maintenance in the vehicle was assessed on the beetle Alphitobius diaperinus (Coleoptera: Tenebrionidae), an insect pest in poultry houses that causes major economic losses [12,13].

\section{MATERIALS AND METHODS}

\subsection{Characterization of the Carrier}

The pyroclastic material (ashes and pumices) was collected in natural accumulations of Villa La Angostura (404' $48^{\prime \prime}$ S, $71^{\circ} 38^{\prime} 46^{\prime \prime} \mathrm{W}$ ), situated at $\sim 40 \mathrm{Km}$ from the source, two months after the eruption (Figure 1). In this area, the depth of accumulated pyroclast was more than $30 \mathrm{~cm}$. Bulk samples were dried and sieved (American Society for Testing and Materials mesh) for analyzing the grain-size distribution.

The pyroclast was examined under a Nikon polarizing microscope through the use of reflected light to visualize the opaque minerals. For this study, the samples were mounted in a resin that had been polished by means of different abrasives. Likewise, sheets of loose grain were prepared for analyzing the vitreous and crystalline particles constituting the volcanic mixture by transmitted light under a polarizing microscope.

Scanning-electron-microscopy measurements were performed in a Phillips 505 ESEM microscope with a tungsten filament and an Everhart-Thornley Detector (a high-vacuum secondary electron detector).

The BET surface area was measured by $\mathrm{N}_{2}$ adsorption with a Micromeritics ASAP 2020 Automated BraunauerEmmet-Teller Sorptometer.

X-ray-diffraction patterns for mineralogical analysis were carried out in a PHILIPS PW 1710 diffractometer, $\mathrm{Cu}$ Ka radiation Ni filtered.

A chemical analysis of the major elements was performed by the technique of inductively coupled plasma atomic-emission spectroscopy (expressed as \% oxides; ALS Chemex Lab, Canada).

Raman spectra-obtained by a Via Renishaw microRaman spectrometer (785.0 nm laser line)-were analyzed by curve-fitting after background subtraction.

Thermal studies were done by means of a Shimadzu TG-50 for differential thermal gravimetric analysis. Additional thermal experiments were carried out in a furnace at controlled temperatures.

\subsection{Fungal Isolate}

The fungal strain used for testing the pyroclastic material as a carrier was $B$. bassiana (LPSC 1067) from the culture collection of the Spegazzini Institute (LPSC), La Plata, Argentina. The choice of this strain was based on its efficacy against pest grasshopper and locust species of Argentina in the laboratory $[14,15]$. Conidia of the fungal 


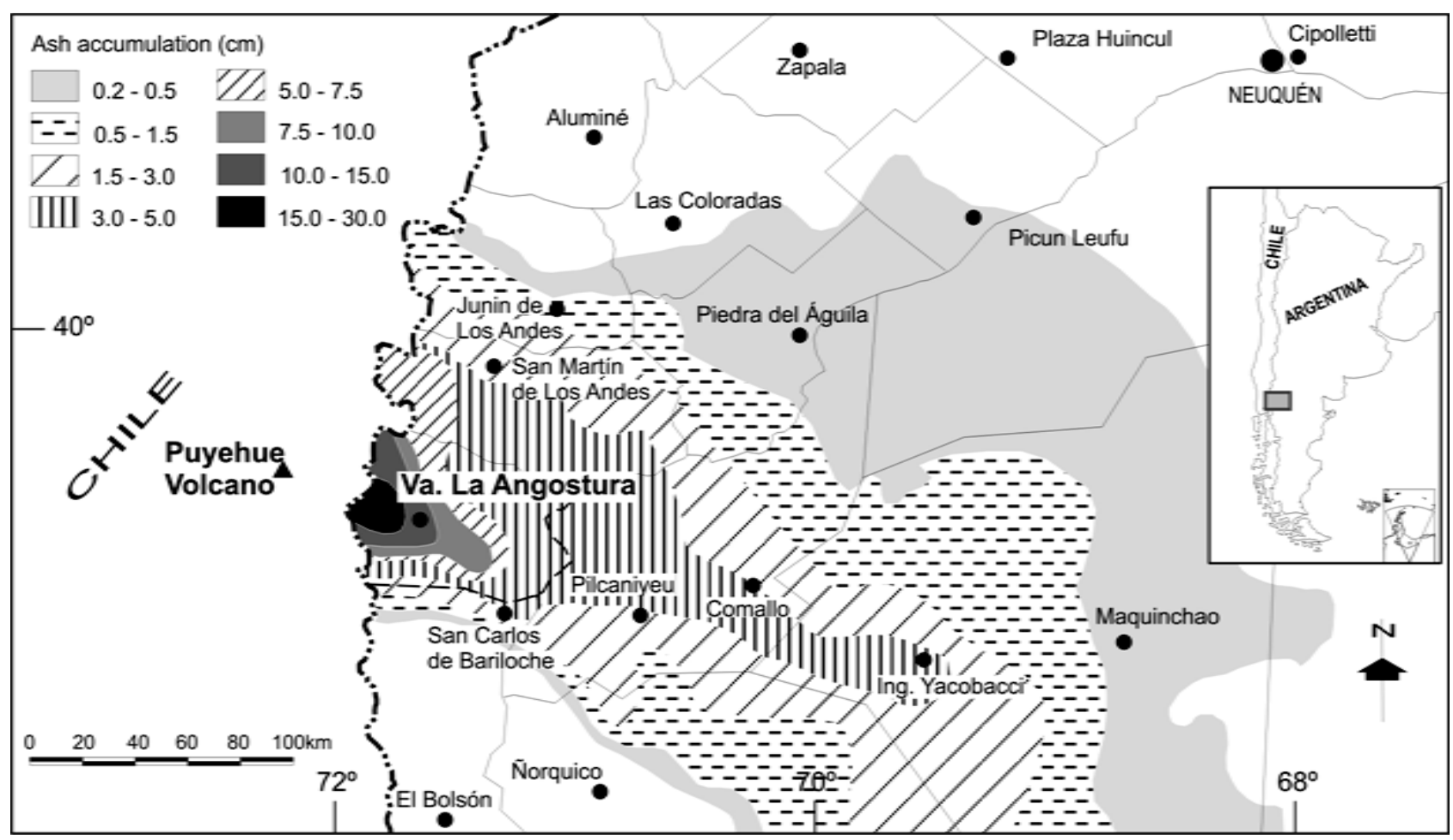

Figure 1. Distribution of the ash fall from the Puyehue-stratovolcano eruption (reported by the Instituto Nacional de Tecnología Agropecuaria, 2011).

strain were obtained from cultures on potato-dextroseagar medium after incubation for 10 days at $25^{\circ} \mathrm{C}$ in the dark.

\subsection{Preparation of the Conidial Suspension}

Conidia were harvested with disposable cell scrapers $\left(\right.$ Fisherbrand $^{\circledR}$ ) from 10-day-old cultures and placed in test tubes containing $0.01 \%(\mathrm{v} / \mathrm{v})$ Tween $80^{\circledR}$ (polyoxyethylene sorbitan monolaurate; Merck). Suspensions were vortexed for $2 \mathrm{~min}$, filtered through four layers of sterile muslin, and adjusted to $1 \times 10^{8}$ conidia. $\mathrm{ml}^{-1}$, according to Geden and Steinkraus [16] after cell counting in a Neubauer hemocytometer.

\subsection{Impregnation in the Pyroclastic Material}

In order to determine if the pyroclast constituted a potential carrier of $B$. bassiana conidia without loss of fungal viability and pathogenicity, the geomaterial was impregnated with the conidial suspension. The volcanic ash was first washed with sterile distilled water and left to dry at room temperature (in a laminar-flow chamber) for $24 \mathrm{~h}$; then $1000 \mathrm{~g}$ were inoculated with a suspension of 1 $\times 10^{8}$ conidia $\mathrm{ml}^{-1}$ of $B$. bassiana and placed in a sterile Erlenmeyer flask that was then capped tightly and stored at room temperature for 18 months. This entire process including the 18-month storage was carried out in triplicate.

\subsection{Viability of the Fungal Conidia}

Fungal-conidial viability was determined as described by Lane et al. [17] both before and after 18 months $[14,15]$. For this purpose, $1 \mathrm{~g}$ of the impregnated volcanic material was removed from the original stored sample and placed in test tubes containing $10 \mathrm{ml}$ of $0.01 \%(\mathrm{v} / \mathrm{v})$ Tween 80 (Merck). The suspension was vortexed for 2 min and filtered through four layers of sterile muslin. Artificial culture medium $(800 \mu l)$ was placed in the form of a thin layer of approximately 2-mm thickness onto a microscope slide (previously sterilized by autoclaving) located in a Petri dish containing filter paper of 100-mm diameter moistened with sterile distilled water. Of the fungal suspension, $400 \mu \mathrm{l}$ were inoculated into the culture medium wetting each slide. The Petri dish containing this culture was incubated at $24^{\circ} \mathrm{C}$ in the dark to facilitate the germination of the spores. After $24 \mathrm{~h}$ the germinated and nongerminated conidia were counted. A conidium was considered germinated when the germ tube reached half its length. Three replicates were performed, and 300 conidia were counted in each one.

\subsection{Pathogenicity Bioassays}

To determine whether the conidia of $B$. bassiana within the volcanic material had conserved their pathogenicity, both before and after the 18-month storage period, $100 \mathrm{~g}$ of the impregnated ash was placed in $90 \times 15 \mathrm{~mm}$ 
sterile Petri dishes together with 12 adults of the pest of poultry houses, the darkling beetle Alphitobius diaperinus (Coleoptera: Tenebrionidae), a coleopteron that causes great economic losses to those producers. The beetles were kept in the Petri dishes with the impregnated pyroclast for 10 days. During the course of the trial all insects were fed ad libitum. At the end of the trial, the dead individuals were counted and immediately transferred to high-humidity chambers (sterile Petri dishes with filter paper dampened with sterile distilled water). Mycosis was confirmed by microscopical examination of the dead beetles. Three replicates of the impregnated ash before storage and five at the conclusion were performed with the treated ashes along with five control replicates undergoing the same treatment but without the fungal inoculum. The ash-treated and control samples were placed at $25^{\circ} \mathrm{C}$ with a $12: 12 \mathrm{~h}$ light:dark photoperiod. The controls were included to exclude the possibility that exposure to the vehicle per se might produce significant mortality.

\subsection{Statistical Analyses}

The Student t-test was used for evaluation of significant differences between the mortality caused by volcanic ash inoculated with conidia of $B$. bassiana and the ash-minus-conidia controls, with the data having been previously square-root transformed.

\section{RESULTS AND DISCUSSION}

\subsection{Characterization of the Carrier}

Figure 2 shows the particle-size-distribution curve of the pyroclastic material, showing that the major proportion corresponds to the size of sand (0.105 to $1.68 \mathrm{~mm}$ ). Likewise, polarizing-microscope studies indicated thepredominance ( $80 \%$ - 90\%) of vitreous fragments; where crystalline phases such as quartz, orthoclase, plagioclase, titanite, iron oxides (magnetite and hematite), and pyrite were observed in minor proportions (not shown). Figure 3(a) shows the more frequent morphology of the individual particles of the pumices, featuring those with subrounded, elongated, and angular shapes (these last in lower proportion). Figure 3(b) provides a detail of a sector containing the pumice fragments at higher magnification where the porous surface becomes clearly distinguishable.

The typical SEM morphology of the pumiceous volcanic material (Figure 4) was dominated by vesiculated particles with few connections among the channels and pores. The average BET-calculated surface area was 2.23 $\mathrm{m}^{2} \mathrm{~g}^{-1}$, indicating pores of $\sim 114 \AA$ within the mesopore size range. On the other hand, the material was found to contain a high degree (72.2\% - 73.4\% of the total volume) of macroporosity by the Hg-sortometer technique, thus indicating a low overall density.

The X-ray-diffraction pattern of the pyroclast indicated a major proportion of an amorphous vitreous phase. The low proportion of crystalline phases, when examined, showed the presence of substituted calcium plagioclase $\left(\mathrm{CaAl}_{2} \mathrm{Si}_{2} \mathrm{O}_{8}\right)$ and pyroxene $\left(\mathrm{Mg}_{2} \mathrm{Si}_{2} \mathrm{O}_{6}\right.$; PowderDiffraction File [PDF] 89-1463, 85-1740, 88-2377). Likewise, iron oxides, observed as weak reflections, can be assigned to binary and/or mixed oxides, e.g. magnetite-type structures (PDF 80-0390) as well as to hematite or related phases (PDF 89-2810).

These crystalline compounds were corroborated by micro-Raman spectroscopy, a technique that reveals the individual components within a mixture of complex composition. Figure 5(a) with lines at 325, 380, 530, 665, 888 and $999 \mathrm{~cm}^{-1}$ corresponds to clinopyroxene (characterized by signals at 322, 667 and $997 \mathrm{~cm}^{-1}$ [18]) and plagioclase (typical strong signal at $510 \mathrm{~cm}^{-1}$ and weak signals in the $1000 \mathrm{~cm}^{-1}$ region [18]). Spectrum of Figure 5(b) shows bands at 221, 290, 406, 605 and 1308 $\mathrm{cm}^{-1}$ indicates the presence of hematite (identified by lines at $\sim 225,291,411,611$ and $\left.1321 \mathrm{~cm}^{-1}[19,20]\right)$ whereas a shoulder at $662 \mathrm{~cm}^{-1}$ could be assigned to magnetite (signal at $\sim 665 \mathrm{~cm}^{-1}[19,20]$ ).

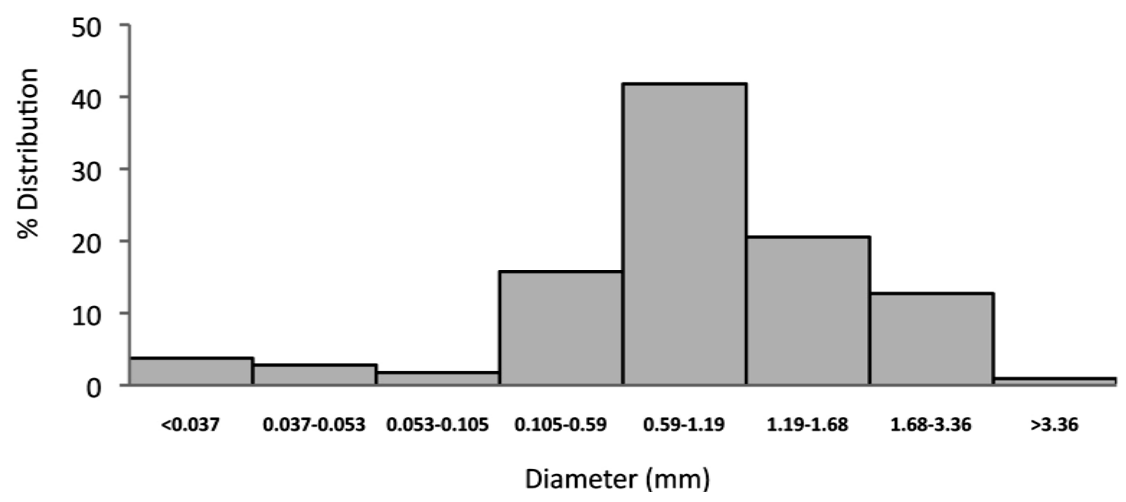

Figure 2. Grain-size-distribution curve. In the figure the percent size distribution is plotted versus the grain diameter in $\mathrm{mm}$. 

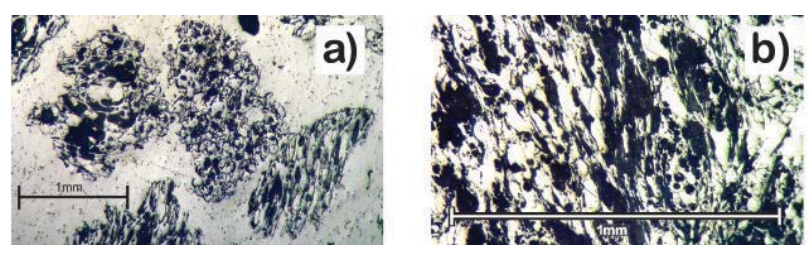

Figure 3. Reflection polarized light microscope images of the pyroclast pumice fragments showing (a) The shapes of the pumices; (b) Details of their porous surface.

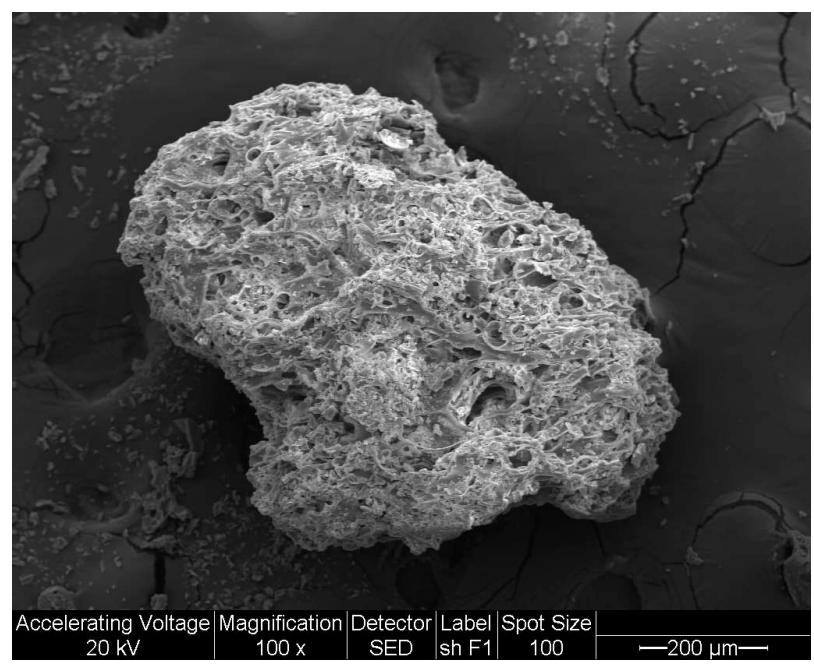

Figure 4. SEM appearance of a typical pumicite grain.
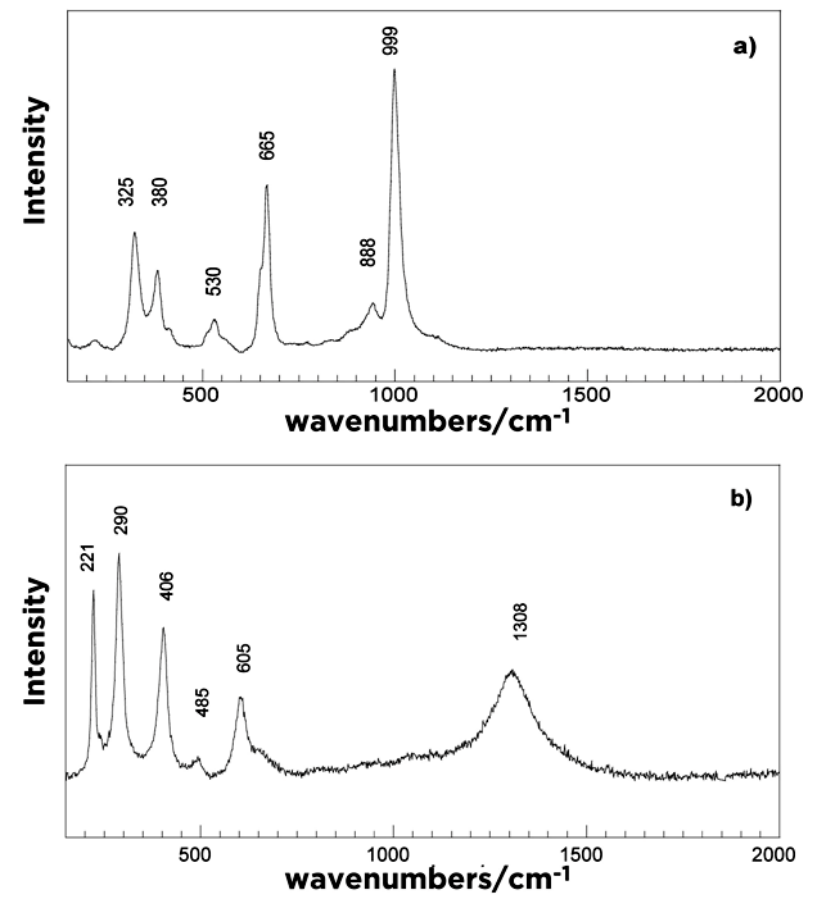

Figure 5. Micro-Raman spectra registered in different point locations within the pyroclast.

The water loss proved variable, depending on the atmospheric moisture. Differential-thermal-gravimetry stu- dies indicated two consecutive weight-loss signals in general: room temperature $(\mathrm{RT})-80^{\circ} \mathrm{C}$ and $80^{\circ} \mathrm{C}-200^{\circ} \mathrm{C}$, suggesting the presence of adsorbed water to different degrees. The pumiceous particles lost $7 \%$ of the adsorbed moisture at $50^{\circ} \mathrm{C}, 14 \%$ at $100^{\circ} \mathrm{C}$ and $18 \%$ at $200^{\circ} \mathrm{C}$. The hydric retention under adequate conditions can reach about $30 \%$. A thermal stability between RT and $800^{\circ} \mathrm{C}$ was indicated by X-ray diffraction, while the dehydration process (between the RT and $\sim 100^{\circ} \mathrm{C}$ ) was reversible-a behavior similar to that observed in zeolite minerals.

Furthermore, the chemical analysis of a dried sample (Table 1) indicated the rhyolite-like composition characteristic of pumiceous material, with an iron content (expressed as $\% \mathrm{Fe}_{2} \mathrm{O}_{3}$ ) of 5.58. Notably, $\mathrm{Ca}, \mathrm{Mg}, \mathrm{Na}, \mathrm{K}$, $\mathrm{Mn}, \mathrm{Ba}, \mathrm{Sr}$, and $\mathrm{P}$ were present as minor components.

\subsection{Use of Volcanic Material as Vehicle of Beauveria bassiana Conidia}

The use of dust carriers may improve the storage of the conidia as well as its distribution and application in the field [21]. Indeed, even under these conditions of nonrefrigeration for such a long period the viability of the B. bassiana (LPSC 1067) conidia was $97.4 \% \pm 0.7 \%$ (where the average initial values were determined at 98.5 \pm 0.8 ). An optimal shelf life of fungal spores under nonrefrigerated storage conditions is of paramount practicality since mycopesticides may be exposed to high temperatures during transport, warehousing, or on-farm storage [22-24]. Therefore, the very high viability determined after this prolonged period of storage demonstrates that the pyroclast obtained after the recent PCCVC eruption is a promising geomaterial for use as a carrier for the biocontrol agent $B$. bassiana and possibly for other fungi.

The SEM micrograph of Figure 6(b) shows the distribution and relative size of the conidia among the particles of the inoculated volcanic ash after 18 months at room temperature. The conidia shown exhibit a certain morphologic deformation, probably an artifactual result of the preparation used for scanning electron microscopy since their viability was as high as $97 \%$ before the preparation of the samples for SEM.

Previous studies indicated that the spore longevity of entomopathogenic fungi was inversely proportional to temperature [25-27]. Blanford et al. [28] studied the interaction between temperature and humidity on the viability of nonformulated $B$. bassiana spores and found half-lifes of decay of 31,49 , and 71 days at $32^{\circ} \mathrm{C}, 26^{\circ} \mathrm{C}$, and $22^{\circ} \mathrm{C}$, respectively, in environments with low relative humidities, but a slower decay in viability with half-lifes of 67 and 117 days at $26^{\circ} \mathrm{C}$ and $22^{\circ} \mathrm{C}$, respectively, in environments with high relative humidities. Therefore, compared to those data with nonformulated spores, the present results showed that the volcanic material tested 
Table 1. Major and minor elements (expressed as \% oxides) by ICP-AES.

\begin{tabular}{cc}
\hline Sample & PM \\
\hline $\mathrm{SiO}_{2}$ & 67.04 \\
$\mathrm{TiO}_{2}$ & 0.89 \\
$\mathrm{Al}_{2} \mathrm{O}_{3}$ & 14.17 \\
$\mathrm{Fe}_{2} \mathrm{O}_{3}$ & 5.58 \\
$\mathrm{MnO}$ & 0.14 \\
$\mathrm{MgO}$ & 1.05 \\
$\mathrm{CaO}$ & 2.95 \\
$\mathrm{Na}$ & 5.04 \\
$\mathrm{~K}_{2} \mathrm{O}$ & 2.37 \\
$\mathrm{P}_{2} \mathrm{O}_{5}$ & 0.17 \\
$\mathrm{BaO}$ & 0.08 \\
$\mathrm{SrO}$ & 0.02 \\
$\mathrm{LOI}$ & 0.50 \\
\hline
\end{tabular}
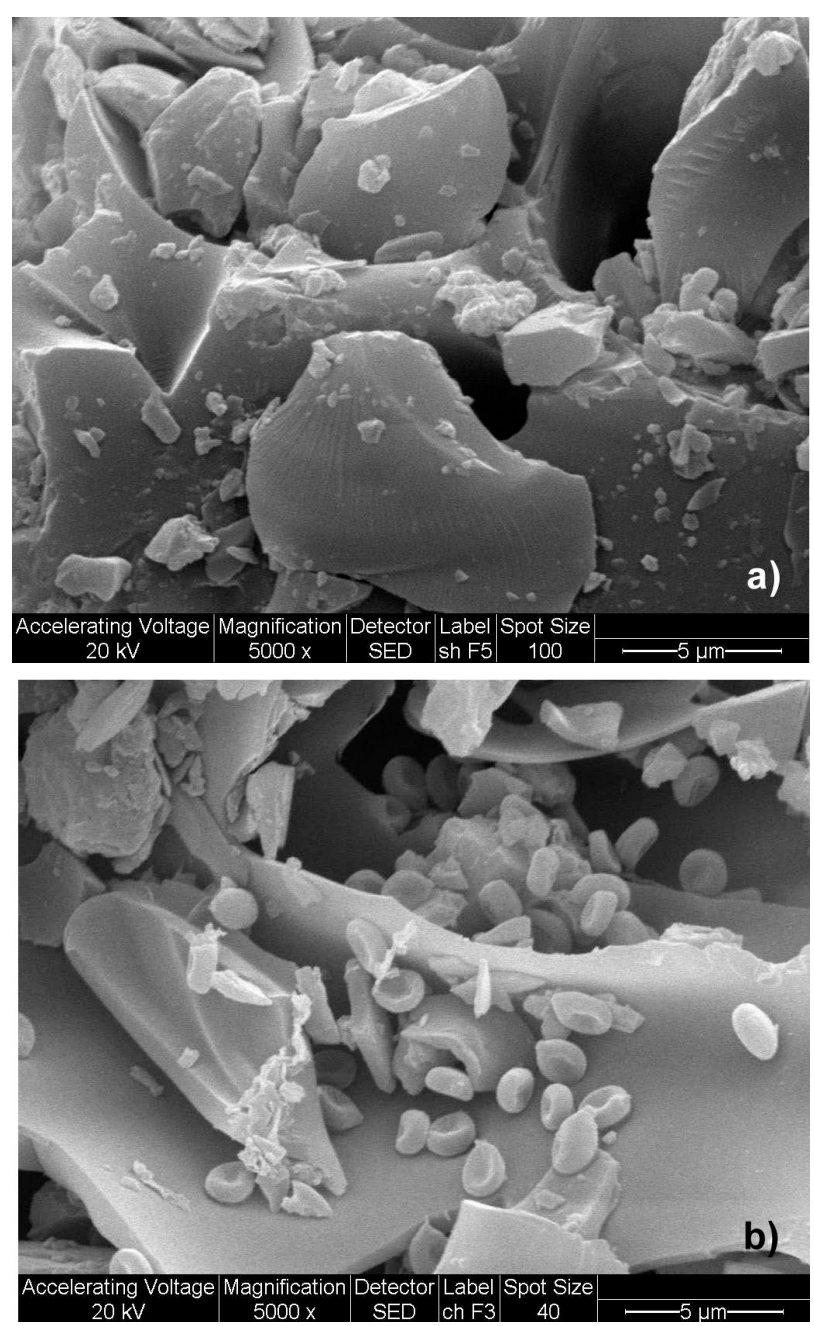

Figure 6. SEM micrograph of (a) The pyroclastic material without $B$. bassiana; (b) The same material impregnated with $B$. bassiana. clearly favoured the prolongation of conidial viability. Since biocontrol products must remain stable for at least one year in order to be commercially acceptable [25]; the utilization of pyroclastic material could constitute a stable, simple, and low-cost vehicle for B. bassiana formulations.

Because of the normal local seasonal variations occurring during the storage period, this formulation (i.e., geomaterial with bioinsecticide) was necessarily subjected to a substantial temperature variability (i.e., $5^{\circ} \mathrm{C}$ $40^{\circ} \mathrm{C}$ ). Nevertheless, this degree of variation did not affect the viability of $B$. bassiana conidia. A physicochemical characterization of the matrix dust used under the conditions of experimental storage (i.e., the mass of the pyroclastic material and the volume of the receptacle) revealed an average weight loss of only $3 \%$ at up to $40^{\circ} \mathrm{C}$ because the loss depended on the nature of the components of the pyroclastic mixture $(0.5 \%$ for the crystalline phases and between $4 \%$ and $6 \%$ for the pumiceous particles). Considerable disagreement exists in literature about the effect of moisture content on the viability of entomopathogenic fungal spores, a question that is even more complicated considering the influence of temperature. Liquid water is cited as diminishing the viability of mycopesticide products by promoting spore germination [25]. Nevertheless, the decline of B. bassiana viability because of high temperatures can be significantly lower at high humidity environments [28]. The specific interactions with water that take place within the mass of this pyroclastic material may produce an environment with a suitable intermediate vapor pressure so as to protect the spores from dessication at high temperatures but still minimize the accumulation of liquid water that would necessarily cause a decline in viability. Therefore, the type of water in the material-i.e., that which is only adsorbed to the vesicles by a net physical process, thus leaving the material subject to a suitable vapor pressure (e.g., from water evaporation in a closed container dependent on the temperature, or by effect of the relative humidity of the environment)-may help prolong the longevity of spores.

Statistical analysis of the pathogenicity bioassays demonstrated that the high percentages of mortality among the insects that were placed in the inoculated volcanic material after 18 months of storage $(63.3 \% \pm 3.5 \%)$ were significantly different $(\mathrm{t}=2.31, \mathrm{p}=0.001)$ from the mortality of those exposed to the control substrate (8.31\% $+0.7 \%$; Figure 7$)$. These results also indicated that contact of the insects with the ash alone produced only minimal mortality. In addition these same mortality determinations when performed on the conidia immediately after impregnation in the volcanic ash gave levels of $65.3 \%$ $\pm 2.5 \%$, which values were statistically indistinguishable from the results represented in the figure (not shown). 
That level of mortality is high, compared to other studies evaluating the effects of $B$. bassiana on darkling beetles [29].

All the dead beetles in contact with the impregnated volcanic material exhibited an external growth of the fungus after a 24-h incubation in a humid chamber, thus demonstrating that death had been caused by mycosis (Figure 8). Darkling beetles represent one of the most pernicious pests in poultry production since they are known to transmit the viruses causing Marek's disease, fowl pox, avian reovirus, infectious bursal disease, and Newcastle disease along with Aspergillus spp. and coccidia $[12,13]$. Because of the physical characteristics of the geomaterial tested, the ashes could be easily spread as a dust carrying $B$. bassiana for the biocontrol of $A$. diaperinus in poultry houses.

\section{CONCLUSION}

The results from bioassays on the killing efficiency of entomopathogenic fungi contained in volcanic materials from the PCCVC as a carrier proved auspicious for the

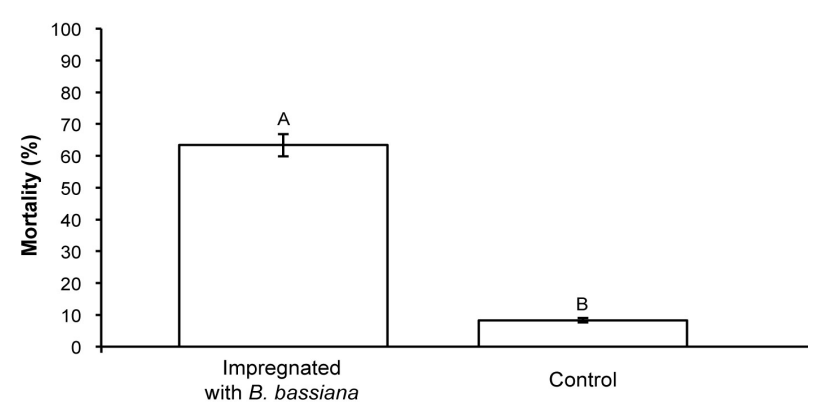

Figure 7. Percent mortality (means $\pm \mathrm{SD}$ ) of Alphitobius diaperinus exposed to volcanic ash impregnated with Beauveria bassiana conidia and the volcanic-ash control. Values with different letter superscripts indicate significant differences according to the Student t-test.

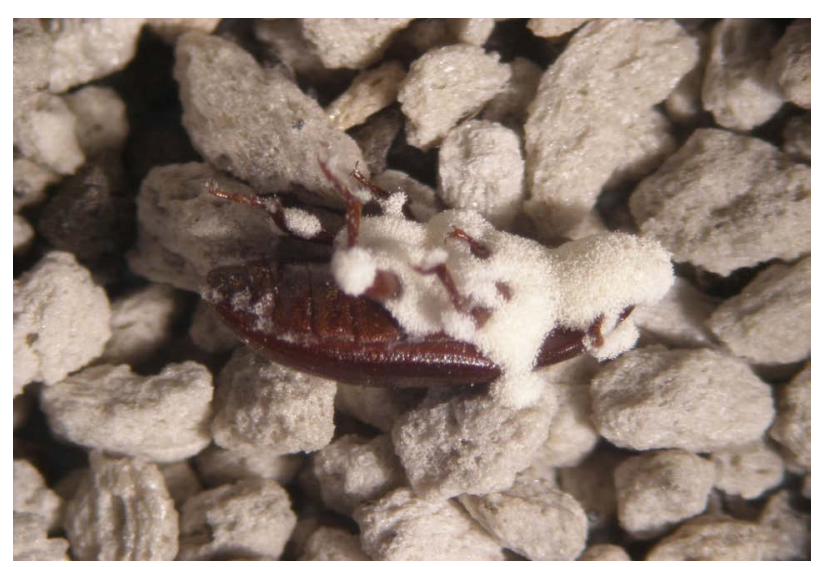

Figure 8. Dead adults of Alphitobius diaperinus (Coleoptera: Tenebrionidae) infected by Beauveria bassiana conidia from impregnated volcanic ash after a 24-h incubation in a humid chamber. eventual utilization of the pyroclast as a bioinsecticide vehicle. The biologic results in combination with the physicochemical properties of the carrier revealed that the formulation is stable for at least 18 months under a wide range of environmental conditions. We believe that the material tested can serve as an excellent substitute for other dust vehicles used to maintain the viability and pathogenicity of conidia of B. bassiana. In conclusion, this geomaterial would appear to be highly suitable for the preparation of formulations for pest control; thus utilizing what would otherwise be volcanic waste as an efficient, abundant, and inexpensive carrier of entomopathogenic fungi.

\section{ACKNOWLEDGEMENTS}

The work was done by financial support of ANPCyT BID 2011 PICT-2186 Argentina. Authors thank Lic. M. Theiller (CINDECA, University of La Plata) for SEM technical measurements. Dr. Donald F. Haggerty, a retired career investigator and native English speaker, edited the final version of the manuscript.

\section{REFERENCES}

[1] SERNAGEOMIN (2011) "Reportes especiales de actividad volcánica complejo volcánico puyehue-Cordón Caulle. www.sernageomin.cl

[2] Horwell, C.J. and Baxter, P. (2006) The respiratory health hazards of volcanic ash: a review for volcanic risk mitigation. Bulletin of Volcanology, 69, 1-24. http://dx.doi.org/10.1007/s00445-006-0052-y

[3] Knowles, D.A. (1998) Formulation of agrochemicals. In: Knowles, D.A., Ed., Chemistry and Technology of Agrochemical Formulations, Kluwer Academic Publishers, The Netherland, 41-79. http://dx.doi.org/10.1007/978-94-011-4956-3_3

[4] Shah, P.A. and Pell, P.K. (2003) Entomopathogenic fungi as biological control agents. Applied Microbiology and Biotechology, 61, 413-423.

[5] Vega, F.E., Goettel, M.S., Blackwell, M., Jackson, M.A., Keller, S., Koike, M., Maniania, N.K., Monzón, A., Ownley, B., Pell, J.K., Rangel, D. and Roy, H.E. (2009) Fungal entomopathogens: New insights on their ecology. Fungal Ecology, 2, 149-159. http://dx.doi.org/10.1016/j.funeco.2009.05.001

[6] Bhattacharyya, S. and Basu, M.K. (1982) Kaolin powder as a fungal carrier. Applied and Environmental Microbiology, 44, 751-753.

[7] Bidochka, M.J., Kamp, A.M. and De Cross, J.N.A. (2000) Insect pathogenic fungi: From genes to populations. In: Kronstad, J.W., Ed., Fungal Pathology, Springer, The Netherlands, 171-193.

[8] Jaronski, S.T. (2010) Ecological factors in the inundative use of fungal entomopathogens. BioControl, 55, 159-185. http://dx.doi.org/10.1007/s10526-009-9248-3

[9] Faria, M.R. and Wraight, S.P. (2007) Mycoinsecticides 
and mycoacaricides: A comprehensive list with worldwide coverage and international classification of formulation types. Biological Control, 43, 237-256. http://dx.doi.org/10.1016/j.biocontrol.2007.08.001

[10] Alves, L.F.A., Gassen, M.H., Pinto, F.G.S., Neves, P.M.O.J. and Alves, S.B. (2005) Natural occurrence of Beauveria bassiana (Bals.) Vuilleman (Moniliales: Moniliaceae) on the lesser mealworm, Alphitobius diaperinus (Panzer) (Coleoptera: Tenebrionidae), in a poultry house in Cascavel, PR. Neotropical Entomology, 34, 507-510. http://dx.doi.org/10.1590/S1519-566X2005000300021

[11] Daoust, R. and Roberts, D. (1983) Studies on the prolonged storage of Metarhizium anisopliae conidia: Effect of temperature and relative humidity on conidial viability and virulence against mosquitoes. Journal of Invertebrate Pathology, 41, 143-150.

http://dx.doi.org/10.1016/0022-2011(83)90213-6

[12] McAllister, J.C., Steelman, C.D., Newberry, L.A. and Skeeles, J.K. (1994) Reservoir competence of the lesser mealworm (Coleoptera: Tenebrionidae) for Salmonella typhimurium (Eubacteriales: Enterobacteriaceae). Journal of Medical Entomology, 31, 369-372.

[13] Goodwin, M.A. and Douglas Waltman, W. (1996) Transmission of Eimeria, viruses, and bacteria to chickens: Darkling beetles (Alphitobius diaperinus) as vectors of pathogens. The Journal of Applied Poultry Research, 5, 51-55.

[14] Pelizza, S.A., Eliades, L.A., Scorsetti, A.C., Cabello, M.N. and Lange, C.E. (2012) Entomopathogenic fungi from Argentina for the control of Schistocerca cancellata (Orthoptera: Acrididae) nymphs: fungal pathogenicity and enzyme activity. Biocontrol Science and Technology, 22, 1119-1129. http://dx.doi.org/10.1080/09583157.2012.713910

[15] Pelizza, S.A., Eliades, L.A., Saparrat, M.C.N, Cabello, M.N., Scorsetti, A.C. and Lange, C.E. (2012) Screening of Argentine native fungal strain for biocontrol of the grasshoppers Tropidacris collaris: Relationship between fungal pathogenicity and chitinolytic enzyme activity. World Journal of Microbiology and Biotechnology, 28, 1359-1366. http://dx.doi.org/10.1007/s11274-011-0935-8

[16] Geden, C.J. and Steinkraus, D.C. (2003) Evaluation of three formulations of Beauveria bassiana for control of lesser mealworm and hide beetle in Georgia poultry houses. Journal of Economic Entomology, 96, 1602-1607. http://dx.doi.org/10.1603/0022-0493-96.5.1602

[17] Lane, B.S., Humphreys, A.M., Thompson, K. and Trinci, A.P.J. (1988) ATP content of stored spores of Paecilomyces farinosus and the use of ATP as criterion of spore viability. Transactions of the British Mycological Society, 90, 109-111. http://dx.doi.org/10.1016/S0007-1536(88)80186-4

[18] Haskin, L., Wang, A., Rockow, K., Jolliff, B., Korotev, R. and Viskupic, K. (1997) Raman spectroscopy for mineral identification and quantification for in situ planetary surface analysis: A point count method. Journal of Geophysical Research, 102, 19293-19306.
http://dx.doi.org/10.1029/97JE01694

[19] Das, S. and Hendry, M.J. (2011) Application of Raman spectroscopy to identify iron minerals commonly found in mine wastes. Chemical Geology, 290, 101-108. http://dx.doi.org/10.1016/j.chemgeo.2011.09.001

[20] Hanesch, M. (2009) Raman spectroscopy of iron oxides and (oxy)hydroxides at low laser power and possible applications in environmental magnetic studies. Geophysical Journal International, 177, 941-948. http://dx.doi.org/10.1111/j.1365-246X.2009.04122.x

[21] Ezzati-Tabrizi, R., Talaei-Hassanloui, R. and Pourian, H.R. (2009) Effect of formulating of Beauveria bassiana conidia on their viability and pathogenicity to the onion thrips, Thrips tabaci Lind. (Thysanoptera: Thripidae), 49, 97-104. http://dx.doi.org/10.2478/v10045-009-0013-5

[22] Hong, T.D., Ellis, R.H. and Moore, D. (1997) Development of a model to predict the effect of temperature and moisture on fungal spore longevity. Annals of Botany, 79, 121-128.

[23] Roberts, D.W. and Leger St., R.J. (2004) Metarhizium spp., cosmopolitan insect pathogenic fungi: Mycological aspect. Advances in Applied Microbiology, 54, 1-70. http://dx.doi.org/10.1016/S0065-2164(04)54001-7

[24] Faria, M., Hotchkiss, J.H. and Wraight, S.P. (2012) Application of modified atmosphere packaging (gas flushing and active packaging) for extending the shelf life of Beauveria bassiana conidia at high temperatures. Biological Control, 61, 78-88.

http://dx.doi.org/10.1016/j.biocontrol.2011.12.008

[25] Jackson, M.A., Dunlap, C.A. and Jaronski, S.T. (2010) Ecological considerations in producing and formulating fungal entomopathogens for use in insect biocontrol. BioControl, 55, 129-145. http://dx.doi.org/10.1007/s10526-009-9240-y

[26] Hong, T.D., Gunn, J., Ellis, R.H., Jenkins, N.E. and Moore, D. (2001) The effect of storage environment on the longevity of conidia of Beauveria bassiana. Mycological Research, 105, 597-602. http://dx.doi.org/10.1017/S0953756201004026

[27] Daoust, R.A., Ward, M.G. and Roberts, D.W. (1983) Effect of formulation on the viability of Metarhizium anisopliae conidia. Journal of Invertebrate Pathology, 41, 151-160. http://dx.doi.org/10.1016/0022-2011(83)90214-8

[28] Blanford, S., Jenkins, N.E., Christian, R., Chan, B.H.K., Luisa, N., Michael, O., Koekemoer, L., Coetzee, M., Read, A.F. and Thomas, M.B. (2012) Storage and persistence of a candidate fungal biopesticide for use against adult malaria vectors. Malaria Journal, 11, 354. http://dx.doi.org/10.1186/1475-2875-11-354 http://www.malariajournal.com/content/11/1/354

[29] Gindin, G., Glazer, I., Mishoutchenko, A. and Samish, M. (2009) Entomopathogenic fungi as a potential control agent against the lesser mealworm, Alphitobius diaperinus in broiler houses. BioControl, 54, 549-558. http://dx.doi.org/10.1007/s10526-008-9205-6 